\title{
CAPÍTULO 15: AFETO E IDENTIDADE LOCAL: UM OLHAR SOBRE OS ESTUDANTES DO BAIRRO DA VÁRZEA - RECIFE (PE)
}

\section{CAPÍTULO 15: AFECTO E IDENTIDAD LOCAL: UNA MIRADA A LOS ALUMNOS DEL BARRIO VÁRZEA - RECIFE (PE) \\ CHAPTER 15: AFFECTION AND LOCAL IDENTITY: A LOOK AT STUDENTS OF VÁRZEA NEIGHBOURHOOD - RECIFE (PE)}

\begin{abstract}
Leandro Neves Bispo de Lima ${ }^{1}$; Whithiney Julho Ribeiro dos Santos Coutinho²; Taynara França da Silva Campelo $^{3}$; Iraneide Pereira da Silva ${ }^{4}$
\end{abstract}

DOI : https://doi.org/10.31692/978-65-88970-03-4.202-208

\section{INTRODUÇÃO}

O trabalho aqui exposto apresenta um recorte dos resultados do Projeto de Extensão intitulado "Turismo e Fotografia: uma proposta de relação com a identidade local", projeto este que tem como público alvo estudantes de Ensino Médio da rede pública de ensino no Recife, mais especificamente os estudantes das escolas do bairro da Várzea, nos arredores do Instituto Federal de Pernambuco - local de origem do mesmo. Para o desenvolvimento deste trabalho foram utilizados dados e experiências obtidas a partir das atividades do projeto nas escolas Senador Novaes Filho e Escola de Referência em Ensino Médio - EREM Olinto Victor.

O recorte apresentado tem por objetivo analisar a relação de afeto e pertencimento do jovem estudante com a fotografia e o local no qual está inserido, fazendo uso de informações fornecidas pelos pesquisados por meio da resposta de questionários de caráter quantitativo e da análise de dados.

Após a introdução será apresentado a fundamentação teórica que tem como objetivo dar base a esse texto, em seguida apresentaremos a metodologia que foi utilizada para elaboração das atividades do projeto, assim como os resultados e discussões obtidos a partir destas, finalmente, apresentam-se as conclusões.

\section{FUNDAMENTAÇÃO TEÓRICA}

A fotografia surge no contexto da Revolução Industrial, entre o fim do século XVIII e

\footnotetext{
${ }^{1}$ Graduando em Gestão de Turismo, Instituto Federal de Pernambuco - IFPE, $\underline{\operatorname{lnbl} @ \text { discente.ifpe.edu.br }}$

${ }^{2}$ Graduando em Gestão de Turismo, Instituto Federal de Pernambuco - IFPE, whithineycoutinho@gmail.com

${ }^{3}$ Graduanda em Gestão de Turismo, Instituto Federal de Pernambuco - IFPE, tfsc@discente.ifpe.edu.br

${ }^{4}$ Doutora em Administração, Instituto Federal de Pernambuco - IFPE, iraneidepereira@recife.ifpe.edu.br
} 
às primeiras décadas do século XIX, ganhando notoriedade e sendo popularizada a partir dos anos de 1860, propiciando o surgimento de verdadeiros impérios industriais e comerciais (KOSSOY, 2014). Ainda segundo Kossoy (2014), esta invenção possibilitou a inovação no contexto de informação e conhecimento, por representar um recorte visual do mundo real. No entanto, ainda de acordo com ele, em seus primeiros momentos de existência, a fotografia servia a propósitos de documentação conjuntamente ao registro escrito, sofrendo certo nível de preconceitos, pois a escrita seria um método mais fácil de descodificar os registros do que a própria imagem.

Com o passar dos anos as imagens foram ganhando mais importância, sendo largamente utilizadas como uma forma de registro dos fatos, além de adentrar à vida social como uma forma de recordação de pessoas e lugares. Assim, a fotografia foi ganhando cada vez mais visibilidade, chegando aos ateliês, museus e servindo de objeto de pesquisa. Essa popularização é abordada por Ferreira e Mello (2016, p. 80):

Com equipamentos cada vez mais práticos e de valor acessível para a população em geral, fotografar tornou-se algo simples, já que desde um simples celular com câmera até às máquinas mais modernas, $\mathrm{o}$ ato de guardar sua recordação de qualquer momento é quase uma obrigação.

A partir da fotografia, a sociedade atual passou a enxergar e compartilhar o mundo à sua maneira, pondo sua visão do mundo em perspetiva e materializando-a, conforme cita Le Goff (1998, p. 119, apud CAMARGO, 2018, p. 118) "o orgulho urbano é feito da imbricação entre a cidade real e a cidade imaginada, sonhada por seus habitantes e por aqueles que a trazem à luz, detentores de poder e artistas", das imbricações possíveis, a relação com o local, o sentimento de pertença, as relações de afeto com espaços e pessoas surgem a partir do que tanto a cidade, como seu registro fotográfico trazem à memória. A autora reforça ainda que:

Cidades, para além do espaço do habitar, do viver em comunidade, são espaços de afeto. Do afetar e do deixar-se afetar. Estar na cidade é estar com pessoas. Milhares. Milhões delas. São Habitantes, visitantes, passantes. É dividir com desconhecidos o conhecimento do território, com-partilhar experiências diversas enquanto semelhantes e dessemelhantes. É viver um senso de comunidade que pode ser simultaneamente - gregário e segregador (CAMARGO, 2018, p. 108).

Ressalta-se ante o exposto, a relevância destes aspectos embasam o debate sobre a construção da identidade local que ocorre a partir não só da relação entre os sujeitos, mas também destes com a natureza, com a atribuição de sentimentos e com os simbolismos dos lugares.

Acrescenta-se que, como lembra Kossoy (2014), a memória, que surgiria como uma dimensão que permite a atuação do passado no presente, pode ser materializada através da 
fotografia, fazendo com os lugares e seus significados fossem reavivados nos sujeitos por meio deste recurso.

Complementando a discussão sobre a construção de afeto com lugares, a constituição da identidade local e do sentimento de pertença, Medeiros (2011, p.55), ao citar o pensamento de Günther et. all. (2003), lembra que:

\begin{abstract}
A identidade do lugar desempenha um papel importante na maneira como o espaço físico é percebido, permitindo que este ganhe significados e despertando sentimentos nos usuários. Transpondo tal ideia em termos práticos, observamos que muitos diálogos e apresentações se iniciam com a pergunta: "de onde você veio?" ou "você é de onde?”; e quando não, esta parece ser uma questão que complementa o imaginário sobre a identidade do outro (MEDEIROS, 2011, p.55).
\end{abstract}

Assim, conhecer os sentimentos que o sujeito possui em relação ao lugar de onde veio ou onde vive pode trazer não somente um melhor entendimento sobre os aspectos que constituem seu conhecimento de mundo, mas também permite entender melhor a forma como eles se identificam com estes locais.

Para conhecer os aspectos ora citados junto aos jovens estudantes do ensino médio da rede pública de ensino moradores do bairro da Várzea, apresenta-se a seguir o processo metodológico da pesquisa realizada com estes sujeitos.

\title{
METODOLOGIA
}

Trata-se de uma pesquisa de abordagem quantitativa que buscou analisar a relação de afeto e pertencimento do jovem estudante com a fotografia e local no qual está inserido. A pesquisa de campo voltou-se para o bairro da Várzea.

Historicamente, o bairro da Várzea era um dos mais importantes da Região Metropolitana do Recife, por nele haver uma grande quantidade de engenhos produtores de açúcar, dentre eles onde estão localizados hoje o atual Instituto Ricardo Brennand, a Paróquia de Nossa Senhora do Rosário, a Praça da Várzea, dentre outros (BARBOSA, 2018).

A partir de dados do Instituto Instituto Nacional de Estudos e Pesquisas Educacionais Anísio Teixeira - INEP (2020), o estado de Pernambuco contava com um total de 1126 estabelecimentos de educação de nível médio no ano de 2019 (INEP, Complementando, de acordo com dados do Instituto Brasileiro de Geografia e Estatística IBGE (2018), a cidade do Recife abrigava um total de 64.142 mil alunos de nível médio naquele ano, sendo 46.772 mil desses integrantes da Rede Estadual de Educação (IBGE, 2018).

Para composição do campo desta pesquisa, inicialmente, foram mapeadas escolas 
públicas de Ensino Médio no entorno do bairro da Várzea. Já no segundo momento foi dado início ao contato com as instituições mapeadas. A partir deste contato, a direção de cada instituição selecionou de forma independente turmas de ensino médio, com aproximadamente 30 alunos para participar das atividades propostas. No total foram realizadas atividades em duas escolas do bairro, a Escola Senador Novaes Filho e a EREM Olinto Victor.

$\mathrm{O}$ instrumento de pesquisa abordou três pontos-base, divididos em 32 questões: o perfil dos respondentes, a fim de compreender quem são, de onde vêm e seu tempo de residência no local; a relação/identidade com o local, para que se possa entender sua percepção do espaço em que vive, suas atividades de lazer e seu consumo cultural e, por fim, a relação turismo e fotografia, procurando saber quais pontos turísticos estes conhecem dentro de uma lista de referência, seu hábito fotográfico e a relação de afeto entre os espaços e a fotografia feita neles. Uma vez colhidos os dados, estes foram tabulados com o uso da plataforma Google Forms e, posteriormente, analisados por meio da estatística descritiva.

\section{RESULTADOS E DISCUSSÃO}

Sobre o significado do bairro da Várzea para os mesmos, os estudantes apontaram: amizade (26,8\%), identidade com o local (26,8\%), família (25,4\%) e história pessoal $(22,5 \%)$, o que converge com o que diz Farias (2011, p. 15):

\footnotetext{
Se pedirmos a qualquer pessoa para que relate uma experiência importante da vida, provavelmente poucas não situarão o local onde ocorreu. Seja uma experiência de raiva, desgosto, grande alegria, fuga, tristeza, terá um significado para a pessoa que a relata, e o local vinculado a essa experiência não estará dissociado de tal sentimento.
}

Tal aspecto corrobora o que traz Camargo (2018) quanto ao papel da cidade que é visto não só como um espaço do habitar, do viver em comunidade, mas também como espaços da construção de afeto com pessoas, lugares e que ajudam a construir sua história. Assim, podemos ainda notar mudanças no conceito de cidade a partir do momento em que esta deixa de ser um conceito geográfico e torna-se um local de memória, como informa Araripe (2004).

Sobre os sentimentos que Recife desperta, os estudantes responderam que ela representa tanto alegria $(52,1 \%)$, como amor (31\%) e ainda felicidade $(29,6 \%)$, reforçando os elementos que constroem afeto e sentimento de pertença com o lugar em que vivem. Complementando as informações sobre o sentimento de pertença e o que representa o bairro para estes sujeitos, $26,8 \%$ indicaram que a Várzea é o local da amizade e da identidade com o local $(26,8 \%)$. 
Ao tratarmos da relação destes jovens com o local, por meio de suas práticas culturais e de lazer, quando questionados sobre as manifestações culturais de que conhecem e/ou participam, 45\% afirmaram que se interessam pelo passinho, expressão de dança ligada ao brega-funk recifense que, de acordo com Conceição (2009, s/p), vem tendo grande participação dos jovens na periferia da cidade, já 33\% disseram se interessar pelo frevo, manifestação cultural tradicional da cidade e do estado de Pernambuco. Já com relação às práticas de lazer realizadas no bairro ou na cidade, os respondentes informaram que nos momentos de lazer, 74\% utilizam-se do tempo livre para ouvir música, 39\% assiste à televisão e 35\% preferem ir ao Shopping, o que reforça a pesquisa feita pela empresa Opinion Box em 2018. Esta pesquisa afirma que cerca de $80 \%$ das pessoas ouve música todos os dias, variando entre o dia todo (26\%) até poucas vezes no dia (29\%). Além disso $28 \%$ dos estudantes afirmam que têm a fotografia como uma atividade de lazer, enquanto $23 \%$ interessam-se por viagens e 5,6\% pelo teatro.

Assim, as informações analisadas indicam que os jovens pesquisados vivem o seu local por meio suas práticas culturais e de lazer, como a construção de sua sociabilidade, o que gera nos mesmos sentimentos de afeto e pertencimento tanto com o bairro da Várzea como com a cidade do Recife.

\section{CONCLUSÕES}

A pesquisa realizada buscou analisar a relação de afeto e pertencimento do jovem estudante do ensino médio da escola pública de ensino e morador do bairro da Várzea em Recife -PE com a fotografia e o local em que está inserido. A partir desta pesquisa, percebe-se que para estes jovens há uma relação de afeto tanto com o bairro, pois ele se constitue como espaço de sociabilidade, pois é onde eles constroem suas amizades (26,8\%); bem como com a cidade do Recife, uma vez que para eles a cidade representa alegria $(52,1 \%)$, amor (31\%) e ainda felicidade $(29,6 \%)$.

Desta forma, as informações analisadas indicam que o bairro, assim como a cidade do Recife, se constituem como espaços de afeto, de construção de sua identidade e que desperta um sentimento de pertença com o local onde realizam suas práticas de lazer e cultura.

Ante o exposto, este estudo buscou contribuir para o conhecimento da relação dos jovens estudantes com o local em que vivem, abrindo espaço para reflexões, discussões e elaboração de pesquisas futuras que aprofundem as questões ligadas à relação de afeto destes sujeitos com o local que habitam. 


\section{REFERÊNCIAS}

ABRAMUS. Consumo de Música no Brasil. Disponível em: $<$ https://www.abramus.org.br/noticias/16444/consumo-de-musica-no-brasil/>. Acesso em: 18 set. 2020 .

ARARIPE, F. M. A. Do patrimônio cultural e seus significados. Transinformação, Campinas , v. 16, n. 2, p. 111-122, Aug. 2004 . Disponível em: $<$ http://www.scielo.br/scielo.php?script $=$ sci arttext\&pid=S0103$37862004000200001 \& \operatorname{lng}=\mathrm{en} \& \mathrm{nrm}=$ iso $>$. Acesso em: 06 Out. 2020.

BARBOSA, M. Bairro da Várzea marcou o início da ocupação de Pernambuco pelos portugueses. Brasil de Fato Pernambuco. Disponível em: $<$ https://www.brasildefatope.com.br/2018/10/31/bairro-da-varzea-marcou-o-inicio-daocupacao-de-pernambuco-pelos-portugueses $>$. Acesso em: 28 set. 2020.

CAMARGO, P . O. Sobre amor, afeto e cidades. Arcos Design. Rio de Janeiro, v. 11, n. 2, Dezembro de 2018, p. 104-122. Disponível em: <https://www.epublicacoes.uerj.br/index.php/arcosdesign/article/view/47519>. Acesso em: 05 out. 2020.

CONCEIÇÃO, J. H. O "passinho dos maloka" de Recife: Um grito de identidade e visibilidade. New Order. 20 de junho de 2019. Disponível em: $<$ https://medium.com/neworder/o-passinho-dos-maloka-de-recife-um-grito-de-identidade-evisibilidade-acfa72d77198>. Acesso em: 06 jul. 2020.

FARIAS, T. M. O afeto além dos muros e portões: o apego a vizinhanças na cidade do Natal. Dissertação (Mestrado em Psicologia) - Universidade Federal do Rio Grande do Norte. Centro de Ciências Humanas, Letras e Artes. Programa de Pós-Graduação em Psicologia. 2011. Natal, Disponível em: $<$ https://repositorio.ufrn.br/jspui/handle/123456789/17514>. Acesso em: 03 out. 2020.

FERREIRA, A. P; MELLO, N. D. Fotografia e Turismo: mudança de olhar do turista. Revista Educação. Guarulhos, 11, n. 2, p. 80-90, 2016. Disponível em: $<$ http://revistas.ung.br/index.php/educacao/article/view/1520>. Acesso em: 30 set. 2020.

INSTITUTO BRASILEIRO DE GEOGRAFIA E ESTATÍSTICA - IBGE. IBGE Cidades@| Pernambuco | Recife | Pesquisa | Censo escolar - sinopse | Ensino básico. Disponível https://cidades.ibge.gov.br/brasil/pe/recife/pesquisa/13/5908?indicador=5913\&tipo=grafico Acesso em: 29 set. 2020.

INSTITUTO NACIONAL DE ESTUDOS E PESQUISAS EDUCACIONAIS TEIXEIRA - INEP. Resumo Técnico: Censo da Educação Básica Estadual 2019 [recurso eletrônico]. Brasília: Instituto Nacional de Estudos e Pesquisas Educacionais Anísio Teixeira, 2020.

Disponível em: $<$ http://portal.inep.gov.br/documents/186968/484154/Resumo+T\%C3\%A9cnico+do+Estado+ de+Pernambuco +-+ Censo + da + Educa $\% C 3 \%$ A7\%C3\%A3o+B $\% C 3 \% A 1$ sica $+2019 / 28 \mathrm{c} 774 \mathrm{bd}-$ 277b-416a-aeb1-5ca49ab392b1?version=1.0>. Acesso em: 29 set. 2020. 
KOSSOY, B. Fotografia \& História. 5. ed. São Paulo: Ateliê Editorial, 2014.

MEDEIROS, S. T. B. F. Um lugar para chamar de "meu". Dissertação (Mestrado em Psicologia) - Universidade Federal do Rio Grande do Norte. Centro de Ciências Humanas, Letras e Artes. Programa de Pós-Graduação em Psicologia. Natal, 2005. Disponível em: $<$ https://repositorio.ufrn.br/jspui/handle/123456789/17528>. Acesso em: 07 out. 2020. 